\title{
Magnitude and factors associated with delayed initiation of breastfeeding among mothers who deliver in Mulago hospital, Uganda.
}

\author{
Richard Kalisa ${ }^{1}$, Ombeva Malande ${ }^{2}$, Jolly Nankunda ${ }^{3}$, James K Tumwine ${ }^{3}$.
}

1. Department of Paediatrics, Ruhengeri district hospital, P.O. Box 54, Musanze, Rwanda.

2. Department of Paediatrics, Faculty of Health Sciences, Egerton University. P.O Box 536-20115. Egerton, Nakuru, Kenya.

3. Department of Paediatrics and Child Health, Makerere University, P.O Box 7072, Kampala.

\begin{abstract}
Background: Breastfeeding as a determinant of infant health and nutrition saves up to 1.5 million infant lives annually. Though breastfeeding is mostly universal in sub-Saharan Africa, early initiation of breastfeeding is rarely practiced.

Objective: To determine magnitude and factors associated with delayed initiation of breastfeeding among mother-infant pairs who deliver in Mulago hospital.

Methods: We carried out a descriptive cross sectional study, where 665 mother-infant pairs were interviewed within 24 hours following delivery; with additional qualitative data collected using focus group discussions to understand reasons for delaying initiation. The data was analysed by identification and coding of themes.

Results: In this study, 31.4\% mothers delayed initiation of breastfeeding. This was associated with maternal HIV positive status (AOR 2.3; 95\% CI 1.3-4.2), inadequate prenatal guidance, (AOR 3.6; 95\% CI 1.9-6.8), inadequate professional assistance to initiate breastfeeding (AOR 1.8; 95\% CI 1.2-2.8) and caesarean section delivery (AOR 8.6; 95\% CI 4.7-16.0). Other reasons were perceived lack of breast milk, need of rest for both mother and baby after labor, and negative cultural beliefs. Conclusion: In Mulago Hospital 1:3 mothers delayed initiation of breastfeeding. The reasons for delayed initiation include; inadequate information during ANC, HIV positive serostatus, caesarian section delivery and negative cultural ideas.
\end{abstract}

Keywords: Breastfeeding, initiation, delayed, HIV

DOI: http://dx.doi.org/10.4314/ahs.v15i4.11

Cite as: Kalisa R, Ombeva OM, Nankunda J, Tumwine JK. Magnitude and factors associated with delayed initiation of breastfeeding among mothers who deliver in Mulago hospital, Uganda. Afri Health Sci. 2015;15(4):1130-5. bttp://dx.doi.org/10.4314/abs.v15i4.11

\section{Introduction}

Delayed initiation of breastfeeding is the failure of the mother to initiate breastfeeding within one hour of delivery or within one hour of recovery of post-operative consciousness in case of those who delivered after spontaneous vaginal delivery and Caesarean section respectively ${ }^{1}$.

Breastfeeding is almost universal in Uganda, with 99\% of all children breastfed for some period of time after

\section{Corresponding author:}

Ombeva Malande,

Department of Paediatrics, Faculty of Health

Sciences, Egerton University. P.O Box 536-20115.

Egerton, Nakuru, Kenya.

Tel: +254722475181

Email: ombevaom@gmail.com birth $^{2}$. However, timing of breastfeeding for all children indicated that initiation to breastfeeding was rather late. Only $42 \%$ of ever-breastfed children are initiated within the first hour of birth, and $14.5 \%$ are not even put to the breast within 24 hours of their birth ${ }^{3}$. We report results of a study which determined the magnitude and factors associated with delayed initiation of breastfeeding in Mulago hospital, Uganda, in order to contribute to interventions to prevent it.

\section{Methods}

\section{Study design and setting}

This was a descriptive cross-sectional study, conducted from January to February 2011 in the maternity ward of Mulago hospital, Uganda's National referral and teaching hospital. A total of 618 and 47 mothers participated in quantitative and qualitative study groups. Mothers with contraindications to breastfeeding or health problems that affected breastfeeding were excluded from 
the study. Babies with postpartum health problems, and those hospitalized in the newborn intensive care unit were also excluded. Written informed consent was obtained from all participating mothers.

\section{Sample size estimation}

Based on a proportion of mothers who delayed initiation of breastfeeding in Ugandan lactation clinic ${ }^{4}$, and using the Kish Leslie formula $a^{5}$ to obtain the sample size for magnitude of delayed initiation to breastfeeding, and the Fleiss formula ${ }^{6,7}$ to calculate sample size for factors associated with delayed initiation to breastfeeding, a sample size of 618 mother-infant pairs was found adequate for the study.

\section{Enrolment of patients}

After obtaining informed consent, 618 volunteer mothers and five Focus Group Discussion (FGD) groups were enrolled. A structured questionnaire was used to collect data by research assistants 24-hours' postpartum. A focus group discussion session comprised 8 - 12 participants, where an assistant took notes while another made observations. There were 5 FGD groups, two comprised primipara mothers, two multipara mothers and one comprising female caregivers who had escorted mothers to the hospital for labour and delivery.

\section{Data management}

Data was entered into Epidata 3.1 and then exported to SPSS version 11.0 for analysis. The chi-square test and binary logistic regression analysis were used to examine the relationship between delayed initiation of breastfeeding and different variables. $P$ values below 0.05 were considered significant and confidence intervals of $95 \%$ used. The analysis of qualitative data was by identifying themes and sub-themes from the information obtained from focus group discussions. Direct quotations from the respondents were used in the presentation of the study findings.

\section{Ethical considerations}

Written informed consent was obtained from all participating mothers. The study was approved by the School of Medicine, Research and Ethics Committee of Makerere University College of Health Sciences; Mulago Hospital Ethics Committee and, the Uganda National Council for Science and Technology.

\section{Results}

Study population and magnitude of delayed initiation of breastfeeding

As shown in Table 1, 31\% (194/618) of the newborns were breastfed more than one hour from birth with median time of initiation of 30(IQR: 20-120) minutes postpartum. $54.7 \%$ of infants were male (338/618), 89.2\% $(551 / 618)$ had a birth weight greater than $2,500 \mathrm{gm}$ and $85 \%(525 / 618)$ infants received breast milk as their first meal. $31.5 \%$ of mothers were $<20$ years old, $40.3 \%$ had no previous breastfeeding experience, $9.2 \%$ were HIV seropositive, $89.6 \%$ had vaginal delivery, $76.4 \%$ had labor lasting $<18$ hours and $40.9 \%$ had $>4$ ANC visits.

Table 1. Facility and mother-infant pair characteristics

\begin{tabular}{|c|c|c|}
\hline Characteristics & $\mathbf{N}$ & $\%$ \\
\hline \multicolumn{3}{|l|}{ Maternal age (years) } \\
\hline$<=20$ & 195 & 31.5 \\
\hline $21-29$ & 318 & 51.5 \\
\hline$>30+$ & 105 & 17.0 \\
\hline \multicolumn{3}{|l|}{ Parity } \\
\hline 1 & 249 & 40.3 \\
\hline $2-3$ & 294 & 47.6 \\
\hline $4+$ & 75 & 12.1 \\
\hline \multicolumn{3}{|l|}{ Duration of labour (hours) } \\
\hline$<18$ & 472 & 76.4 \\
\hline$>18+$ & 146 & 23.6 \\
\hline \multicolumn{3}{|l|}{ Maternal HIV status } \\
\hline Positive & 57 & 9.2 \\
\hline Negative & 556 & 90.0 \\
\hline Unknown & 5 & 0.8 \\
\hline \multicolumn{3}{|l|}{ Gestational age (weeks) } \\
\hline$<37$ & 67 & 10.8 \\
\hline $37+$ & 551 & 89.2 \\
\hline \multicolumn{3}{|l|}{ Mode of delivery } \\
\hline SVD & 554 & 89.6 \\
\hline Caesarian & 64 & 10.4 \\
\hline \multicolumn{3}{|c|}{ Frequency of antenatal care attendance } \\
\hline Not recommended $(\mathrm{O}-3)$ & 365 & 59.1 \\
\hline Recommended $(4+)$ & 253 & 40.9 \\
\hline \multicolumn{3}{|c|}{$\begin{array}{l}\text { Prenatal guidance on advantages of } \\
\text { breastfeeding }\end{array}$} \\
\hline Yes & 559 & 90.5 \\
\hline No & 59 & 9.5 \\
\hline
\end{tabular}


Maternal, infant, health unit and socio-cultural factors associated with delayed initiation of breastfeeding.

As shown in Table 2, on Bivariate analysis delayed initiation was attributed to night delivery, HIV sero-positiv- ity, prolonged labor, caesarean section delivery, paternal occupation, lack of prenatal guidance on advantages of breast feeding, failure to perform rooming-in or skin to skin practice.

Table 2. Factors associated with delayed initiation of breastfeeding on Bivariate analysis.

\begin{tabular}{|c|c|c|c|c|}
\hline Characteristics & $\begin{array}{l}\text { Frequency } \\
\mathrm{N}=618(\%)\end{array}$ & $\begin{array}{l}\text { Late } \\
\text { initiators } \\
\mathrm{N}=194(\%)\end{array}$ & $\begin{array}{c}\text { OR } \\
(95 \% \mathrm{C} 1)\end{array}$ & P-value \\
\hline \multicolumn{5}{|c|}{ Maternal age (years) } \\
\hline$<=20$ & $195(31.6)$ & $60(30.9)$ & $0.9(0.7-1.5)$ & 0.821 \\
\hline$>21+$ & $423(68.4)$ & $134(69.1)$ & & \\
\hline \multicolumn{5}{|l|}{ Parity } \\
\hline 1 & $249(40.3)$ & $80(41.2)$ & $1.1(0.7-1.3)$ & 0.746 \\
\hline $2+$ & $369(59.7)$ & $114(58.8)$ & & \\
\hline \multicolumn{5}{|c|}{ Duration of labour (hours) } \\
\hline $18+$ & $146(23.6)$ & $58(29.9)$ & $1.6(1.2-2.8)$ & 0.013 \\
\hline$<18$ & $472(76.4)$ & $136(70.1)$ & & \\
\hline \multicolumn{5}{|c|}{ Maternal HIV status } \\
\hline Positive & $57(9.3)$ & $25(13.0)$ & $1.8(1.0-3.1)$ & 0.035 \\
\hline Negative & $555(90.7)$ & $168(87.0)$ & & \\
\hline \multicolumn{5}{|c|}{ Gestational age (weeks) } \\
\hline$<=37$ & $67(10.8)$ & $24(12.4)$ & $1.3(0.7-2.1)$ & 0.408 \\
\hline $37+$ & $551(89.2)$ & $170(87.6)$ & & \\
\hline \multicolumn{5}{|c|}{ Hour of birth (hours) } \\
\hline Night (19-05) & $285(46.1)$ & $102(52.6)$ & $1.5(1.0-2.1)$ & 0.029 \\
\hline Day $(06-18)$ & $333(53.9)$ & $92(47.4)$ & & \\
\hline \multicolumn{5}{|l|}{ Mode of delivery } \\
\hline SVD & $64(10.4)$ & $46(23.7)$ & $7.0(3.9-13)$ & $<0.01$ \\
\hline Caesarian & $554(89.6)$ & $148(76.3)$ & & \\
\hline \multicolumn{5}{|c|}{$\begin{array}{l}\text { Prenatal guidance on advantages of } \\
\text { breastfeeding }\end{array}$} \\
\hline No & $59(9.5)$ & $37(19.1)$ & $0.2(0.1-0.4)$ & $<0.01$ \\
\hline Yes & $559(90.5)$ & $157(80.9)$ & & \\
\hline \multicolumn{5}{|c|}{$\begin{array}{l}\text { Mother received professional } \\
\text { assistance to initiate breast feeding }\end{array}$} \\
\hline No & $327(52.9)$ & $125(64.4)$ & $2(1.4-2.8)$ & $<0.01$ \\
\hline Yes & $291(47.1)$ & $69(35.6)$ & & \\
\hline
\end{tabular}

Table 3 shows that factors independently associated with delayed initiation of breastfeeding were inadequate information to mothers during ANC, HIV positive serostatus and caesarian section delivery. 
Table 3: Factors independently associated with delayed initiation of breastfeeding

\begin{tabular}{|c|c|c|c|c|c|c|}
\hline Variable & $\begin{array}{l}\begin{array}{l}\text { Freque } \\
\text { ncy }\end{array} \\
(618) \%\end{array}$ & $\begin{array}{l}\text { Late } \\
\text { initia } \\
\text { tors } \\
(194) \\
\%\end{array}$ & $\begin{array}{c}\mathrm{COR}^{*} \\
(95 \% \mathrm{CI})\end{array}$ & $\begin{array}{l}\text { p- } \\
\text { Value }\end{array}$ & $\begin{array}{c}\mathrm{AOR}^{*} \\
(95 \% \mathrm{CI})\end{array}$ & $\begin{array}{l}\text { p- } \\
\text { Value }\end{array}$ \\
\hline $\begin{array}{l}\text { Maternal HIV Positive } \\
\text { status }\end{array}$ & $57(9.2)$ & $\begin{array}{l}25 \\
(12.9)\end{array}$ & $1.8(1.0-3.1)$ & 0.035 & $2.3(1.3-4.2)$ & 0.006 \\
\hline $\begin{array}{l}\text { Lack of prenatal } \\
\text { guidance on } \\
\text { advantages of } \\
\text { breastfeeding }\end{array}$ & $59(9.5)$ & $\begin{array}{l}37 \\
(19.1)\end{array}$ & $0.2(0.1-0.4)$ & $<0.01$ & $3.6(1.9-6.8)$ & $<0.01$ \\
\hline $\begin{array}{l}\text { Mother's who didn't } \\
\text { receive professional } \\
\text { assistance to initiate } \\
\text { breast feeding }\end{array}$ & $\begin{array}{l}327 \\
(52.9)\end{array}$ & $\begin{array}{l}125 \\
(64.4)\end{array}$ & $2.0(1.4-2.8)$ & $<0.01$ & $1.8(1.2-2.8)$ & \\
\hline $\begin{array}{l}\text { Delivery by Caesarian } \\
\text { section }\end{array}$ & $\begin{array}{l}64 \\
(10.4) \\
\end{array}$ & $\begin{array}{l}46 \\
(23.7)\end{array}$ & $7.0(3.9-13)$ & $<0.01$ & $8.6(4.7-1.6)$ & \\
\hline
\end{tabular}

COR* - Denotes Crude Odds ratio

AOR* - Denotes Adjusted Odds ratio

Focus group discussion reasons for delaying initiation

Lack of breast milk was a reason given by most mothers who reported delaying initiation. As one mother said, "...I didn't give breast milk because there was none in the breast, so I squeezed it and realized that nothing at all was coming out..." A few mothers who reported insufficient milk beld that: "...the explanation given was that it would be unfair to give the baby an empty breast to satisfy the infant..."

Maternal HIV infection also contributed to delayed initiation. One affected mother said. "...before delivery I had decided to breastfeed immediately as we had been taught during ANC but after seeing my baby I delayed to decide on whether to start breast feeding or not...."

Mother's beliefs about colostrum too were linked to delayed initiation. One respondent said,... "I didn't give the first breast milk to my baby on the first day after birth because I had been told by my mother to wait until the next day when the first breast milk mixes with the second breast milk..."

Another reason given about belief on colostrum was that it is "dirty" as said by one respondent... "I squeezed the first breast milk away until the white milk came because the former wasn't good; my mother-in-law prepared mushroom soup mixed with local butter and gave my baby about 3 drops until the third day when the first milk mixes with the second..."

Mothers who delivered by caesarean section delayed initiation. One said... "T was exhausted, sleepy and had severe abdominal pain from the wound and feared to breastfeed, so my sister-in-law prepared some sugar water solution for my baby until abdominal pain subsided before I started to breastfeed ..."

Some mothers and babies needed to rest after labor. One mother said: ... "I started to breast feed after the abdominal pain, dizziness and weakness bad reduced and l could sit to breastfeed the baby...” Another mother said "...after delivery my mother-in-law bathed it with hot water, wrapped it and put it to sleep. My mother-in-law told me not to touch bim because be needed rest..."

\section{Discussion}

The magnitude of delayed initiation of breastfeeding of $31.4 \%$ in this study is considered "good" by the World Health Organization. ${ }^{8}$ This rate is much lower than that of previous studies in Uganda which reported $83.7 \%$ and $43.3 \%$ respectively ${ }^{4,9}$. However, data from our study and previous studies are comparable, since they were obtained using same methodology. This was a cross-sectional design where information on breastfeeding was gathered directly from the mothers within 24 hours after delivery. The progressive decline in the rate of delayed initiation of breastfeeding in Uganda may be due to generative positive attitudes and activities by a series of governmental and non-governmental initiatives aimed at promoting early initiation of breastfeeding. 
Similar to our results, caesarean section was the main contributor to delayed initiation of breastfeeding ${ }^{7,10}$. The respondents attributed it to being exhausted, sleepy and severe abdominal pain from the wound. Some studies have however failed to show such a relationship. ${ }^{10,11}$ In Mulago hospital, the trends indicate a marked and increasing divergence with caesarean section rates on the private ward rising to around 50\% compared to $20 \%$ among public deliveries ${ }^{12}$; possibly suggesting that measures preventing caesarean section without medical indication should be implemented. These measures may also aim at preventing elective cesarean sections performed for indications including mothers delivery phobia, or who prefers delivery comfort, requests cesarean section, or when she is influenced by the gynecologist. ${ }^{13}$ Babies delivered by caesarean section were usually given some sugar-water solution until the mothers pain has subsided after which she begins to breastfeed. Prelactal feeding should therefore be avoided and mothers who have delivered by caesarean section should be given extra support while still in the labour suit to ensure early breastfeeding initiation.

As noted in FGDs, inadequate information to mothers during ANC visits was associated with delayed initiation, probably since the focus is on exclusive breastfeeding, PMTCT and encouraging mothers to deliver from health facilities. This focus needs to be broadened to include early initiation of breastfeeding. This is in agreement with Scot J et al who indicated that "implementation of pre-natal and postnatal support programs, along with prenatal education programs among low-income women" had a positive effect on initiation of breastfeeding ${ }^{14}$. The use of peer counselors has been found to be an effective strategy for increasing the practice of exclusive breastfeeding in Africa ${ }^{15}$, and though not yet studied, it is possible that the peer educators can similarly be utilized to educate and improve on reduction of the current high rates of delayed initiation to breastfeeding. The benefits of frequent counseling shown earlier in increasing uptake of exclusive breastfeeding practices ${ }^{16,17}$, can be leveraged in improving early initiation of breastfeeding. This can be done either through community based group counselling ${ }^{15}$, or as individualized peer counselling ${ }^{18}$.

Negative cultural beliefs on colostrum and traditional rituals especially performed on twins before initiation of breastfeeding also exist in many other African cultures $^{10,19}$. The beliefs may also be addressed through peer counselling. HIV positive mothers said they feared to infect their infants with HIV in spite of assurances to the contrary from ANC lessons. Similar circumstantial evidence has been reported among South African women who feared to spread HIV to their infants through breast milk ${ }^{20}$ despite recent studies on the overwhelming benefits of antiretroviral drugs for PMTCT ${ }^{21,22}$.

\section{Conclusion}

One in three women who deliver from Mulago hospital delays to initiate breastfeeding. Reasons for late initiation include inadequate information to mothers during antenatal clinic visits, caesarean section delivery, maternal HIV positive serostatus and cultural factors.

\section{Competing interests}

The authors declare that they have no competing interests.

\section{Acknowledgement}

This work was part of a Thesis submitted by Dr. Richard Kalisa in partial fulfillment of the requirements for award of Makerere University Masters of Medicine (M.Med) degree in Paediatrics and Child Health. Many thanks to Ivan Lyazi for statistical assistance; the research assistants and all mothers and infants who participated in the study.

\section{References}

1. WHO. Evidence for the ten steps to successful breastfeeding. Geneva: World Health Organisation; 1998.

2. Wamani H, Tylleskar T, Astrom AN, Tumwine JK, Peterson S: Mothers' education but not fathers' education, household assests or land ownership is the best predictor of child health inequalities in rural Uganda. Int J Equity Health 2004,3:9

3. Uganda Bureau of Statistics (UBOS) and Macro International Inc. 2007. Uganda Demographic and Health Survey 2006. Calverton, Maryland, USA: UBOS and Macro International Inc.

4. Mukasa GK. A 12-month lactation clinic experience in Uganda. J Trop Pediatr. 1992 Apr; 38(2):78-82.

5. Kish Leslie, Survey sampling. John Wiley and Sons New York, 1965: 1-50

6. Fleiss JL, Levin B and Paik MC (2003) Statistical Methods for Rates and Proportions, 3rd Edition. New York: John Wiley \& Sons

7. Emel O, Songuil Y, Madenda Y. Factors associated with breastfeeding initiation time in a Baby-Friendly Hospital. The Turkish Journal of Pediatrics.2010; 52:10-6. 8.http://whqlibdoc.who.int/publications / 2003/ 9241562544.pdf: (accessed June 27, 2008). 
9. Oyang W, Mworozi E, Kiguli S. Prevalence and factors associated exclusive breastfeeding among mother-infant pairs in Kawempe division. Kampala: Makerere University; 2007(Dissertation).

10. Awi DD, Alikor EA. Barriers to timely initiation of breastfeeding among mothers of healthy full-term babies who deliver at the University of Port Harcourt Teaching Hospital. Niger J Clin Pract. 2006 Jun; 9(1):5764.

11. Rowe-Murray HJ, Fisher JR. Baby friendly hospital practices: cesarean section is a persistent barrier to early initiation of breastfeeding. Birth. 2002 Jun; 29(2):12431.

12. Ackers L, Porter C, Byamugisha J. The Liverpool-Mulago partnership Annual Benchmarking Report (1) 2010.

13. Penn Z, Ghaem-Maghami S. Indications for cesarean section. Best Pract Res Clin Obstet Gynaecol 2001; 5: 1-15.

14. Scott JA, Binns CW. Factors associated with the initiation and duration of breastfeeding: a review of the literature. Breastfeed Rev 1999; 7:5-16.

15. Thorkild Tylleskär, Debra Jackson, Nicolas Meda, Ingunn Marie S Engebretsen, Jolly K Nankunda, James $\mathrm{K}$ Tumwine et al, Exclusive breastfeeding promotion by peer counsellors in sub-Saharan Africa (PROMISE-EBF): a cluster-randomised trial. Lancet 2011; 378: 420-27

16. Nankunda J, Tylleskär T, Ndeezi G, Semiyaga N, Tumwine JK. Establishing individual peer counseling for exclusive breastfeeding in Uganda: implications for scaling-up. Matern Child Nutr 2010;6:53-66

17. Nankunda J, Tumwine JK, Soltvedt A, Semiyaga N, Ndeezi G, Tylleskär T. Community based peer counsellors for support of exclusive breastfeeding experiences form rural Uganda. Int Breastfeed J 2006; I:19

18. Nankunda J, Tumwine JK, Nankabirwa V, Tylleskär T. Study Group PE. She would sit with me": mothers' experiences of individual peer support for exclusive breastfeeding in Uganda. Int Breastfeed J 2010;5:16

19. Gunnlaugsson G, da Silva MC, Smedman L. Determinants of delayed initiation of breastfeeding: a community and hospital study from Guinea-Bissau. Int J Epidemiol. 1992 Oct; 21(5):935-40.

20. Thairu LN, Pelto GH, Rollins NC, Bland RM, Ntshangase $\mathrm{N}$ : Socio-cultural influences on infant feeding decisions among HIV-infected women in rural Kwa-Zulu Natal, South Africa. Matern Child Nutr 2005,1:2-10 PubMed

21. Chasela CS, Hudgens MG, Jamieson DJ, et al. Maternal or infant antiretroviral drugs to reduce HIV-1 transmission. N Engl J Med. Jun 17; 362(24);2271-81 22. Elise A, Marie-Louise N, Didier KE. Prevalence of resistance to nevirapine in mothers and children after single-dose exposure to prevent vertical transmission of HIV-1: a meta-analysis. International Journal Epid.2007 May 11;36:1009-21

23. Kiarie JN, Richardson BA, Mbori-Ngacha D, et al. Infant feeding practices of women in a perinatal HIV1 prevention study in Nairobi, Kenya. J Acquir Immune Defic Syndr.2004 Jan 1;35(1):75-81 